\title{
Research Paper: Identifying and Explaining the Factors Affecting the Social Participation of the Iranian People in Natural Disasters
}

\author{
Gholamreza Khademipour $^{1^{*}}$, Hamidreza Khankeh² (D) \\ 1. Medical Emergency Management Center, Kerman University of Medical Sciences, Kerman, Iran. \\ 2. Health Research Center, Department of Emergencies and Natural Disasters, University of Social Welfare and Rehabilitation Sciences, Tehran, Iran.
}

\begin{tabular}{|l|l|}
\hline $\begin{array}{l}\text { Use yourdevic to scan } \\
\text { and read the article online }\end{array}$ & $\begin{array}{l}\text { Citation: Khademipour Gh, Khankeh H. Identifying and Explaining the Factors Affecting the Social Participation of the Ira- } \\
\text { nian People in Natural Disasters. Health in Emergencies and Disasters Quarterly. 2019; 4(4):185-192. http://dx.doi.org/10.32598/ } \\
\text { hdq.4.4.185 }\end{array}$ \\
dol: $:$ http://dx.doi.org/10.32598/hdq.4.4.185
\end{tabular}

\section{(i) (3)}

Article info:

Received: 12 Dec 2018

Accepted: 23 Apr 2019

Available Online: 01 Jul 2019

\section{Keywords:}

Emergencies and natural disasters, Social participation, Iran

\begin{abstract}
Background: Every year, over 200 million people worldwide suffer from life-threatening emergencies and natural disasters. By participating in crisis management, different people and various sectors of the society can reduce the country's vulnerability to natural disasters. One of the most critical issues in crisis management is the participation of people in all of its processes. This partnership is done by people without the legal requirements and to help themselves and others at risk. An adequate understanding of the critical factors affecting people's participation in crisis management can result in controlling these factors, giving appropriate direction to the public assistance in the community and making the necessary coordination between governmental and non-governmental resources leading to greater synergy and effectiveness in activities related to the disaster response phase.
\end{abstract}

Materials and Methods: The purpose of this qualitative content analysis was to identify and analyze the factors affecting social participation in natural disasters in Iran. Based on the findings of this study, we identified the social-intellectual authority of the community, the public's perception of the state, the existence of trustworthy relief organizations, perceived social trust (trust in risk communication), cohesion, solidarity and social relations (social belonging), executive contexts of the community participation in crisis management, subjective perceptions and beliefs of the community members, people's attitude towards society (fundamental trust) as effective factors in social participation in natural disasters in Iran.

Results: The findings of this study showed that an increase and improvement in the process of social participation in disasters requires modifying social interactions and relationships, redesigning the structure and functioning of the associated organizations, improving social and psychological behaviors, as well as providing the context.

Conclusion: These are necessary for the active and efficient participation of individuals and social organizations in case of natural disasters.

\footnotetext{
* Corresponding Author:

Gholamreza Khademipour, PhD candidate.
}

Address: Medical Emergency Management Center, Kerman University of Medical Sciences, Kerman, Iran.

E-mail: khadem115@yahoo.com 


\section{Introduction}

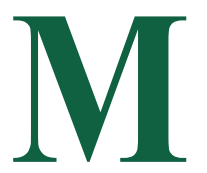

ore than 200 million people worldwide suffer from life-threatening injuries and disasters annually [1]. In countries at higher risk and those which are less prepared for natural disasters, injuries, and damages from natural disasters use up to $5 \%$ of their gross domestic product [2]. By participating in crisis management processes, different people and strata of the society can reduce the country's vulnerability to disasters. Public participation in risk reduction programs and activities can reduce the consequences of natural disasters [3].

Iran is one of the countries that are considered with the highest risk of natural disasters, such as floods, earthquakes, and droughts. It is always regarded as one of the most dangerous regions of the earth, at the risk of earthquakes [4]. Certainly, quick actions toward disasters are beyond the abilities of the governments, and reducing the casualties requires using resources provided by Non-Governmental Organizations (NGOs), which in turn, requires an interaction between the government and society [5].

One of the most critical issues in crisis management is the participation of people in all processes of crisis management. People and society do these relief activities without any legal requirements, but based on social responsibility to assist themselves and others at risk [6]. Iran has always faced numerous disastrous incidents due to its location on the earthquake belt as well as climatic variability. About $77 \%$ of most populous Iranian cities are located in the seismic faults zones, and about $34 \%$ of these cities are exposed to floods.

NGOs have been widely involved in natural disasters in Iran. They could transfer financial supports and trained people to the affected areas. The participation of NGOs in the crisis management process can have different effects [7]. Lessons learned from disasters such as the January 9 earthquake in Bam show the extent of the NGOs' involvement in disaster relief [8]. Kermanshah earthquake in November 2008 created a large volume of public assistance and the presence of volunteers in the affected areas, indicating a high level of social participation in disaster relief [9].

To achieve a coherent and integrated program of disaster management, it is critical to organize and direct public assistance and social participation in emergencies. Proper planning to promote social participation in natural disasters requires sufficient knowledge about society.
Identifying the factors affecting the extent and manner of community participation in different phases of the crisis management can help decision-makers, officials and managers involved in disaster management [10]. Social participation is a sense of belonging, active participation, and voluntary cooperation with social programs and situations based on individuals' non-profit willingness [11]

There are different approaches to the factors influencing social participation. In the psychological approach, based on the motivational factors proposed by McClelland, Hagen's personality factors, and cultural factors of social lack of power and alienation proposed by Rogers, variables related to individuals are considered [12]. Using a behavioral approach, John Watson considers social participation as an assessment criterion of individuals' past circumstances, backgrounds, actions, and also as the cost-benefit of their social activities. A sociological or institutional approach is also one of the approaches looking for factors affecting individuals' social participation in social processes, such as mass media, literate society, urbanization, and social relationships [13].

No scientific studies have yet been conducted to identify and clarify factors associated with social participation and explore the causes of voluntary relief among Iranian people at the time of a disaster. We aimed to investigate the underlying and effective factors on social participation in emergencies and natural disasters, considering the social participation experiences in natural disaster management in Iran. Highlighting these factors may provide a basis for developing a program regarding effective social participation in natural disasters. By adequate understanding of the critical factors affecting social involvement in crisis management, authorities can appropriately direct people's assistance and create greater coordination between governmental and non-governmental organizations, more synergy, and effectiveness in activities related to the disaster response phase. This study aimed at identifying and evaluating the factors affecting social participation in natural disasters in Iran.

\section{Materials and Methods}

This study used a qualitative content analysis approach. The statistical population consisted of the experts, university teachers, and authorities in crisis management of the Kerman University of Medical Sciences, University of Shahid Bahonar, Kerman, Tehran University of Medical Sciences, and the Islamic Azad University, Kerman Branch. Instructors and faculty members in the fields of Health Care Management, Social Medicine, Communication Sciences, Crisis Management, Sociology, Futures 
Studies, Psychology, and Nursing participated in the sampling. Non-probability purposive sampling was performed. The sampling process continued to reach data saturation. In other words, interviews with subsequent people continued until no new data were found in the categories, and saturation was established between the categories of verified relationships (Table 1).

In this study, interviews were held with 12 people. To increase the validity and reliability of the data, a plurality and member control strategy were used. Then, the final extracted sample of the collected data was presented to 5 selected interviewers. After studying the proposed text of the theory, the selected experts suggested their opinions, which were reviewed and considered.

Pluralism strategies were implemented by diversifying the interviewees in terms of educational level, academic background, and specialized disciplines. The data collected after the interviews with the experts were converted from audio files to simple texts, and after the initial coding, each paragraph was subdivided into smaller components. Comments and events of each paragraph were grouped into a nominal category. Then, the categories related to the research topic were identified and determined using the open coding method. The concepts derived from each category were identified, and the main classes or underpinnings of the factors influencing social participation in natural disasters were formed. In other words, all of the initial codes with similar meaning and concepts were subdivided into a single category, and a common concept devoted to comprehending the meaning of all codes was assigned [14].

In the next step, conceptual codes form the main categories and the categories of the same type, created the conceptual classes of the study so that the conceptual categories had the necessary semantic coverage over all their components (primary codes, secondary codes, categories, and concepts) [15]. Finally, the triaxial model illustrated the factors affecting social participation in natural crises in Iran in three main sections.

\section{Results}

Out of 12 interviews with the experts, 605 open-source codes (level 1 concepts) were extracted based on the sentences and paragraphs converted to the conceptual components (Table 2). By classifying similar concepts of level 1, the level 2 concepts eventually yielded 298 items. By combining level 2 concepts and having more general and unified themes, 76 items from the level 3 concepts were obtained. To achieve the themes related to social participation in natural disasters, we subdivided all similar concepts from level 3 into one theme or level 4 concepts, so that they were classified into 4 themes. The themes from this phase of research had a semantic and conceptual integration with level 1, level 2 , and level 3 concepts.

To identify the main factors affecting social participation in natural disasters, homogenous themes grouped

Table 1. Interview

Interview No. 1

Interview

Extracted Basic Concepts

People in the Bam earthquake experienced a wrong method of assistance to the victims of the earthquake. Many people personally distributed their aids to Bam victims. At the same time, people spread rumors that the donations were distributed inaccurate and unfair. The people of Bam, who rushed to help the earthquake-stricken town of Zarand in 2004, exactly followed the same approach and instead of providing the aid to relief organizations, transported and distributed humanitarian aids to Zarand with private vehicles. Relief organizations have not yet announced a specific mechanism to inform the public about the aid distribution. That is why the people who have sent aid to the victims are skeptical about the fair distribution of humanitarian assistance. Indeed, people think that by personally providing aids to the affected people, they will be more happy and content. On the other hand, people expect the government and relief agencies to be strong and wealthy enough to do so with no need for public aid. People have not been adequately trained for emergencies.
A wrong experience and method of assistance

Inaccurate and unfair distribution of public aid

Informing people about how aid is distributed

Equal distribution of public assistance

The capacity of government agencies

Role of religious beliefs in helping people in need

Lack of people's participation in educational programs 
Table 2. The process and number of the concepts of level 1, 2, and 3, themes, and main groups

\begin{tabular}{cc}
\hline Stage & Number \\
\hline Concepts of level 1 & 605 \\
\hline Concepts of level 2 & 298 \\
Concepts of level 3 & 76 \\
\hline Concepts of level 4 (themes) & 24 \\
\hline Main groups & 8 \\
\hline & $\begin{array}{c}\text { |llealth in } \\
\text { Emergencies and [D]isasters [Oluarterly }\end{array}$ \\
\hline
\end{tabular}

Table 3. The themes and main groups for social participation in natural disasters

\begin{tabular}{|c|c|}
\hline Group & Concepts of Level 4 (Themes) \\
\hline $\begin{array}{l}\text { The social-intellectual authority of } \\
\text { the community }\end{array}$ & $\begin{array}{l}\text { 1. The quality and extent of governmental activity in cyberspace and informal social groups } \\
\text { 2. Level of activity of the intellectual reference groups, including youth, adolescents, and masses } \\
\text { in cyberspace }\end{array}$ \\
\hline Public opinion on the government & $\begin{array}{l}\text { 1. A transparent system of collecting and distributing public assistance in natural disasters } \\
\text { 2. The level of dedication in disaster relief organizations } \\
\text { 3. The readiness of aid organizations and agencies } \\
\text { 4. The level of social expectations of the government services }\end{array}$ \\
\hline Reliable relief organizations & $\begin{array}{l}\text { 1. Experience of an unequal distribution of aid and discrimination in relief } \\
\text { 2. General knowledge about corruption in the structure of administration } \\
\text { 3. Public awareness about the dissatisfaction of the affected people with the aid distribution } \\
\text { 4. The individual experience of previous natural events as a suffered person }\end{array}$ \\
\hline $\begin{array}{l}\text { Perceived social trust (trust in risk } \\
\text { communication) }\end{array}$ & $\begin{array}{l}\text { 1. Complete and transparent dissemination of the incident information and its dimensions } \\
\text { 2. The perceived integrity of the social media community } \\
\text { 3. The level of government agencies' concern regarding the occurrence of the disasters and the } \\
\text { injuries' conditions } \\
\text { 4. The extent to which government agencies try to meet the needs of the affected people } \\
\text { 5. Prioritizing government agencies to meet the needs of the affected people by routine govern- } \\
\text { ment programs } \\
\text { 6. The existence of credible and trustful media }\end{array}$ \\
\hline $\begin{array}{l}\text { Cohesion, solidarity, and social } \\
\text { relations in the society (social affili- } \\
\text { ation) }\end{array}$ & $\begin{array}{l}\text { 1. Intercultural and inter-ethnic relations and interactions in society } \\
\text { 2. The level of interpersonal trust in society } \\
\text { 3. The existence of political, cultural and economic barriers to social activities } \\
\text { 4. Coordination of legislative branches at the time of a disaster }\end{array}$ \\
\hline $\begin{array}{l}\text { Executive contexts of the commu- } \\
\text { nity participation in crisis manage- } \\
\text { ment }\end{array}$ & $\begin{array}{l}\text { 1. People's participation in the preparedness and response phase } \\
\text { 2. The flexibility of government agencies to recruit and deploy grassroots volunteers }\end{array}$ \\
\hline $\begin{array}{c}\text { Mental perceptions and community } \\
\text { beliefs }\end{array}$ & $\begin{array}{l}\text { 1. Religious and cultural perspectives on helping } \\
\text { 2. Fatalism attitudes towards natural disasters }\end{array}$ \\
\hline $\begin{array}{l}\text { People's attitudes towards society } \\
\text { (fundamental trust in society) }\end{array}$ & 1. Meeting the basic needs and meeting the needs of people at an early age \\
\hline
\end{tabular}


Table 4. Analysis of the factors affecting social participation in natural crises in Iran based on trilogy triaxial model

\begin{tabular}{|c|c|c|}
\hline \multicolumn{3}{|c|}{ Factors Affecting Social Participation in Natural Crises in Iran } \\
\hline Structural Factors & Behavioral Factors & Underlying Factors \\
\hline $\begin{array}{l}\text { Reliable relief organizations } \\
\text { Cohesion, solidarity and social relations of } \\
\text { the society (social belonging) }\end{array}$ & $\begin{array}{l}\text { The social-intellectual authority of the } \\
\text { community } \\
\text { Public perception of society } \\
\text { Perceived social trust (trust in risk com- } \\
\text { munication) }\end{array}$ & $\begin{array}{l}\text { Executive contexts of the community } \\
\text { participation in crisis management } \\
\text { Mental perceptions and the community's } \\
\text { beliefs } \\
\text { People's attitude towards society (funda- } \\
\text { mental trust) }\end{array}$ \\
\hline
\end{tabular}

into eight. All eight groups of this phase of the study had comprehensive semantic dominance over the previous components. The process and the number of the concepts of level 1, 2, and 3, themes, and constituting groups of the contributing factors for social participation in natural crises are illustrated in Table 3.

Based on the findings of this study, community-based social authority, community's general understanding of the state, existence of the trusted relief organizations, perceived social trust (trust in risk communication), cohesion, solidarity, and community's social relationships (social belonging), executive contexts of the community's participation in crisis management, community's subjective perceptions and beliefs, and individuals' attitudes towards society (fundamental trust) were identified as effective factors of social involvement in natural crises in Iran. These factors can be considered as the main elements influencing the extent and manner of people's participation in community-based relief in unexpected events. The overall analysis of the identified factors based on the triaxial pattern shows that 3 underlying, 3 behavioral, and 2 structural elements are effective on Iranian people's participation in natural disasters (Table 4).

Based on the triaxial model, organizing the factors effective on social participation in natural disasters in Iran requires interventions in three areas: redesigning structural elements, modifying behavioral factors, and creating and strengthening the underlying factors.

\section{Discussion}

The findings of this study showed that increasing and improving the process of social participation in disasters requires modifying social interactions and relationships, redesigning the structure and functioning of the associated organizations, improving social and psychological behaviors, as well as providing the contexts. According to the results of this study, promoting useful social participation indicators in natural crises is not possible solely through the formulation of administrative guidelines and non-psychological mechanisms without considering sociological considerations.

Organizing people-centered behaviors at the time of earthquakes or floods and helping victims voluntarily in Iran requires comprehensive and long-term solutions and also improving the manner of managers, relief organizations, and institutions responsible for large-scale management as well as reform and improvement of social attitudes and confidence.

Newport et al. in their study entitled "Social Participation and Public Awareness in Disaster Risk Reduction," identified contingency plans and emergency preparedness as key factors affecting people's participation in disasters [11]. The results of their study are consistent with the results of the present study and the factors associated with the subgroup of executive contexts of social participation in crisis management and community-based programs.

This study suggests that interpersonal relationships and interactions in society and the level of internal cohesion in society can influence social participation in natural crises. This finding is in line with the results of Madianou et al. study [16]. The subjective perceptions and dominance of fatalistic beliefs were considered as other factors affecting social participation. In other similar studies, like Talò et al., cultural contexts have been identified as an effective factor in people's involvement in natural disasters [17].

Based on the factors identified in this study, and to reinforce and enhance the effective participation of people 
in natural disasters, we recommend the following items. These items are based on the obtained findings and the eight main factors affecting social participation in natural disasters. They are recommended to use as the main strategies in the framework of a comprehensive and long-term plan aimed at organizing, developing and executing the Iranian's participation in natural disasters.

Modification of the intellectual authority of society using mass communication networks and media

Given the shift of the intellectual authority of the community towards new social networks and media, as well as the gap caused by the lack of authentic social reference groups and effective and widespread involvement of social professionals, it is suggested that authorities in the crisis management be actively and constantly present at social networks. They are also recommended to gradually reform the community's intellectual authority in emergencies from unqualified and ineligible persons (celebrities) to the legitimate and competent intellectual authorities.

Transparency in the distribution of resources and public aid

It is recommended to develop a transparent and responsive software system addressing the needs of the affected areas and monitoring the moment-to-moment process of collecting and distributing public aid to change the public perception about the government and relief agencies.

\section{Increasing the preparedness and reporting capa- bilities}

To improve public perception about the government, relief and service organizations should focus their efforts on increasing their readiness by upgrading equipment and human resources and also their ability to respond to unexpected events through influential media and before the events.

Making a balance between the community expectations and real capacities

Improving and changing the public's inappropriate perception towards government and relief agencies by prioritizing the level of community expectations of service delivery in major natural disasters and making a balance between the community expectations and the ability to respond to the needs of disaster management by the officials should be considered.

\section{Reporting the dedicated actions}

It is essential to document and accurately reflect the devotional actions by the relief agencies in natural and unexpected disasters. Avoiding exaggeration at the same time and aiming at improving the public's perception towards government and relief agencies are also significant.

\section{Corruption cleanup in relief agencies}

Trust in relief organizations should be strengthened through preventive mechanisms and serious and effective dealing with any corruption in the service delivery institutions during the crisis.

\section{Timely notification and announcement}

Immediate and truthful information on the severity, extent, and consequences of natural disasters are needed to enhance the perceived social confidence through the intellectual references and trustful media of the community.

\section{Honesty in risk communication}

All news and information about the incident should be presented in plain language, without any complexity or ambiguity of the content, expressing the honesty of the media and officials towards the people.

Increasing empathy with the community

Considering the concern and regret of the government, officials and authorities should notice the incident and the casualties by the cancellation of the preplanned programs, trips, and events to express their empathy and understanding to the community.

\section{Organizing and training the media}

To enhance the perceived social trust and improve risk communication, organizing, training, and utilizing social media, mobile-based news channels, and community-influenced and trusted media in the preparatory and predisaster phase should continually be included in the training programs of the trustees and executive agencies to transmit incident information and the performance of relief organizations and agencies. 
Respecting professional ethics and avoiding party hub settlement in emergencies

Educating political organizations on how to integrate with government agencies and also not taking debilitating positions in emergencies to reinforce social belonging and community cohesion is crucial. This should be implemented and included in the associations' investigations as well as the statutes of political organizations.

Building trust in the community by handing over the jobs to people in emergencies

Since trust between the state and society is a two-way relationship, rebuilding public trust in the government requires building trust in the state. In this regard, government agencies are suggested to hand over the management of the distribution of resources and public and state aid to the affected people and take the first step in rebuilding the mistrust gap.

Respecting the role of the community in the preparatory phase

Ensuring the maximum social participation in the formulation and implementation of relief organizations' predisaster preparedness plans and also the observation and utilization of social capacities in planning, training, and performing exercises should be considered. Preparedness can inform people about their real capacity to respond to disasters and increase public confidence in service organizations and institutions in emergencies.

Reforming religious attitudes toward helping the affected people

Clergy and religious leaders, by emphasizing on the fact that there is no need to be present in the affected areas, should reform the community's attitude towards direct and immediate assistance to the affected people.

\section{Increasing fundamental confidence}

Strengthening the key components affecting basic trust (sense of security, sense of social identity, and sense of individual identity) using educational and cultural practices are needed to foster and develop social confidence in individuals [18].

\section{Conclusion}

The reason for the discrepancy between the results of the present study and other studies, such as Talò et al. research, may be attributed to the profound social and religious differences in the studied communities. Based on the results of this study, the effective, efficient, and systematic social participation in emergencies and natural disasters requires the application and considering its 25 components.

\section{Ethical Considerations}

Compliance with ethical guidelines

All ethical principles were considered in this article.

Funding

This research did not receive any specific grant from funding agencies in the public, commercial, or not-forprofit sectors.

\section{Authors' contributions}

All authors contributed in designing, running, and writing all parts of the research.

\section{Conflict of interest}

The authors declared no conflict of interest.

\section{References}

[1] Guha-Sapir D, Hargitt D, Hoyois P. Thirty years of natural disasters 1974-2003: The numbers. Belgium: Presses universitaires de Louvains 2004.

[2] Kellenberg DK, Mobarak AM. Does rising income increase or decrease damage risk from natural disasters? Journal of Urban Economics. 2008; 63(3):788-802. [DOI:10.1016/j. jue.2007.05.003]

[3] Chen LC, Liu YC, Chan KC. Integrated community-based disaster management program in Taiwan: A case study of Shang-An village. Natural Hazards. 2006; 37(1-2):209. [DOI:10.1007/s11069-005-4669-5]

[4] Peduzzi P, Dao H, Herold C, Mouton F. Assessing global exposure and vulnerability towards natural hazards: The disaster risk index. Natural Hazards and Earth System Sciences. 2009; 9(4):1149-59. [DOI:10.5194/nhess-9-1149-2009]

[5] Bajek R, Matsuda Y, Okada N. Japan's Jishu-bosai-soshiki community activities: Analysis of its role in participatory community disaster risk management. Natural Hazards. 2008; 44(2):281-92. [DOI:10.1007/s11069-007-9107-4]

[6] Kafle S. K., \& Murshed, Z. Community-based disaster risk management for local authorities. Asian Disaster Preparedness Center. Bangkok; 2006. 
[7] Fallahi, A. Lessons learned from the housing reconstruction following the Bam earthquake in Iran. Australian Journal of Emergency Management. 2007; 22(1):26-35.

[8] Abolghasemi H, Radfar MH, Khatami M, Nia MS, Amid A, Briggs SM. International medical response to a natural disaster: Lessons learned from the Bam earthquake experience. Prehospital and Disaster Medicine. 2006; 21(3):141-7. [DOI:10.1017/S1049023X00003599] [PMID]

[9] Ahmadi A, Bazargan-Hejazi S. 2017 Kermanshah earthquake: Lessons learned. Journal of Injury and Violence Research. 2018; 10(1):1-2. [DOI:10.5249/jivr.v10i1.1049]

[10] Warner JF, Waalewijn P, Hilhorst DJM. Public participation in disaster-prone watersheds : Time for multi-stakeholder platforms. Wageningen: Leerstoelgroep Rurale Ontwikkelingssociologie. 2002; 6:1-37.

[11] Newport JK, Jawahar GG. Community participation and public awareness in disaster mitigation. Disaster Prevention and Management: An International Journal. 2003; 12(1):33-6. [DOI:10.1108/09653560310463838]

[12] Rowe G, Frewer L.J. Public participation methods: A framework for evaluation. Science, Technology, \& Human Values. 2000; 25(1):3-29. [DOI:10.1177/016224390002500101]

[13] Dickman AJ. Complexities of conflict: The importance of considering social factors for effectively resolving humanwildlife conflict. Animal Conservation. 2010; 13(5):458-66. [DOI:10.1111/j.1469-1795.2010.00368.x]

[14] Khankeh HR, Khorasani-Zavareh D, Johanson E, Mohammadi R, Ahmadi F, Mohammadi R. Disaster health-related challenges and requirements: A grounded theory study in Iran. Prehospital and Disaster Medicine. 2011; 26(3):151-8. https://doi.org/10.1017/S1049023X11004924 [DOI:10.1017/ S1049023X11006200] [PMID]

[15] Charmaz K, Belgrave LL. Grounded theory. The Blackwell Encyclopedia of Sociology. 2015 October 26 [DOI:10.1002/9781405165518.wbeosg070]

[16] Madianou M, Longboan L. Ong JC. Finding a voice through humanitarian technologies? Communication technologies and participation in disaster recovery. International Journal of Communication. 2015; 9:3020-38.

[17] Talò C, Mannarini T, Rochira A. Sense of community and community participation: A meta-analytic review. Social indicators research. 2014; 117(1):1-28. [DOI:10.1007/s11205-0130347-2]

[18] Child J. Trust-the fundamental bond in global collaboration. Organizational dynamics. 2001; 29(4): 274-88. [DOI:10.1016/ S0090-2616(01)00033-X] 